\title{
The mechanical properties of brick containing recycled concrete aggregate and polyethylene terephthalate waste as sand replacement
}

\author{
Faisal Sheikh Khalid $^{1 *}$, Nurul Bazilah Azmi ${ }^{1}$, Puteri Natasya Mazenan ${ }^{1}$, Shahiron \\ Shahidan ${ }^{1}$, and Noorwirdawati $\mathrm{Ali}^{1}$ \\ ${ }^{1}$ Jamilus Research Centre for Sustainable Construction (JRC), Faculty of Civil and Environmental \\ Engineering, Universiti Tun Hussein Onn Malaysia, Johor, Malaysia
}

\begin{abstract}
This research focuses on the performance of composite sand cement brick containing recycle concrete aggregate and waste polyethylene terephthalate. This study aims to determine the mechanical properties such as compressive strength and water absorption of composite brick containing recycled concrete aggregate (RCA) and polyethylene terephthalate (PET) waste. The bricks specimens were prepared by using $100 \%$ natural sand, they were then replaced by RCA at $25 \%, 50 \%$ and $75 \%$ with proportions of PET consists of $0.5 \%, 1.0 \%$ and $1.5 \%$ by weight of natural sand. Based on the results of compressive strength, only RCA $25 \%$ with $0.5 \%$ PET achieve lower strength than normal bricks while others showed a high strength. However, all design mix reaches strength more than $7 \mathrm{~N} / \mathrm{mm}^{2}$ as expected. Besides that, the most favorable mix design that achieves high compressive strength is $75 \%$ of RCA with $0.5 \%$ PET.
\end{abstract}

\section{Introduction}

Cement and sand bricks are a type of bricks that is commonly used in low and medium cost housing development and other commercial constructions in Malaysia since it is easy to produce and cheap [1]. However, there is an issue in producing these materials especially in developing areas where manufactures find it difficult to locate adequate sources of natural cement and aggregate supply [2-3]. Polyethylene Terephthalate (PET) bottles are nonbiodegradable substance brings quite problematic because it stays longer in the environment [3]. Bottle waste in food and beverage industries already constitute about $10 \%$ of total municipal solid waste [4]. Moreover, PET bottles can produce uncontrolled fire or contaminate the soil and vegetation if the materials be disposed by dumping or burning [56].

Earlier research work has shown the potential of using Recycle Concrete Aggregate (RFA) in engineering applications. According to Kumar et al. [7], in order to increase the compressive strength of RFA, these can be improve by the addition of fiber. In addition, aggregates are represented for $70-80 \%$ of the concrete components therefore it will be

\footnotetext{
*Corresponding author: faisalsh@,uthm.edu.my
} 
beneficial on preserves a recycle demolished concrete as natural aggregate besides to solve the environmental problems [8-9].

When RCA is demolished by using crusher, it can produce aggregate which the particle of aggregate have variety of sizes and can be categorized by its size either coarse or fine aggregate. Evangelista et al. [9] and Khatib [10] interest in using RCA as fine aggregates in construction materials. They mentioned that fine aggregate would not contribute in the reduction of compressive strength and elastic modulus. Thus, there is a huge potential on substitution of RCA as a fine aggregates in construction materials such as brick. The previous study stated that the value of water absorption of concrete with RCA aggregates is higher compared to concrete with natural aggregate [11]. The durability of RCA seems less durable compared to the NA. It is due to the ratio coarse aggregate replacement and the concrete age itself, make the RA less durable compared to the NA because it has high porosity value. The replacement of natural aggregate from 5 to $100 \%$ with the recycled aggregate reduce their compressive strength by 5 to $25 \%$. The water absorbability of RCA is higher, up to $24 \%$ compared with the NAC. As stated by Irwan et al. [12] that the compressive strength of concrete containing all types of PET-aggregates are similar to conventional concrete. However, the strength starts decreasing when the volume of PET replacement up to $2.5 \%$. Therefore, the volume replacement is very significant to study to determine the optimum replacement of natural sand.

One of the possibilities is to utilize the RCA and PET bottle wastes as fine aggregate replacement. Therefore, this study aims to investigate the potential of RCA and fine PET wastes as partial replacement fine material compared to conventional sand cement brick. Therefore, the compressive strength and water absorption tests were conducted to meet the objective of the study.

\section{Methodology}

The design mix for sand cement brick used accordance with BS EN 998-2, where the prescribed mortar for masonry cement sand is $1: 3$ and it categorized in class M6. The optimum design mix of composite brick was $0.5 \%, 1.0 \%$ and $1.5 \%$ of PET and $25 \%, 50 \%$, $75 \%$ of RCA, respectively as partial sand replacement. The brick moulded with a mould size of $215 \mathrm{~mm}$ in length, $105 \mathrm{~mm}$ in width, and $65 \mathrm{~mm}$ in depth. Curing is a process that involves the maintenance of a suitable moisture content and temperature in samples for a suitable period of time immediately after placing and finishing so that desired properties of samples can be achieved. After pressing, the bricks were stacked on timber palettes and marked according to their percentage of aggregate composition.

\section{Results and discussions}

\subsection{Density Test}

The results for density against ages for each percentage of RCA and PET in composite sand cement brick were shown in Figure 1. The density steadily decreased with the increasing of RCA and PET content in the mixtures. RCA and PET were known as a material that has low density, which proved the replacement of sand with these materials contributed to the reduction in mass of the brick samples. In addition, the lower value of specific gravity of recycled aggregates and PET shows that these fine aggregates are lighter than that of natural fine aggregates. 


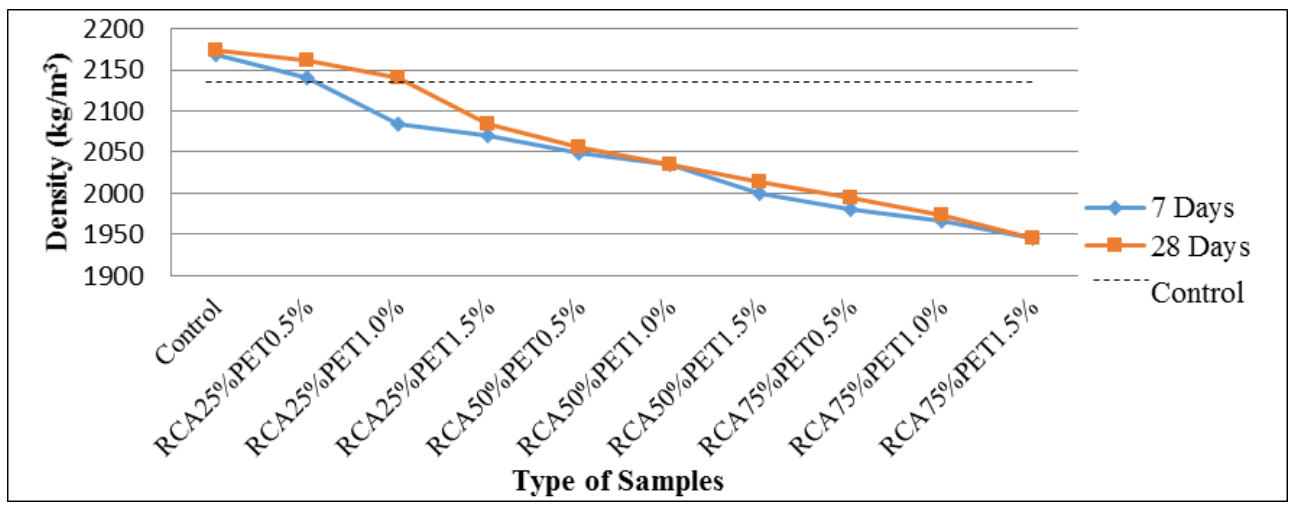

Fig. 1. The average density of composite sand cement bricks with RCA and PET versus.

\subsection{Compressive strength}

It can be seen clearly that the strength of composite brick on 28 days shows that the strength starts to increase as the replacement of waste is increasing as shown in Fig. 2.

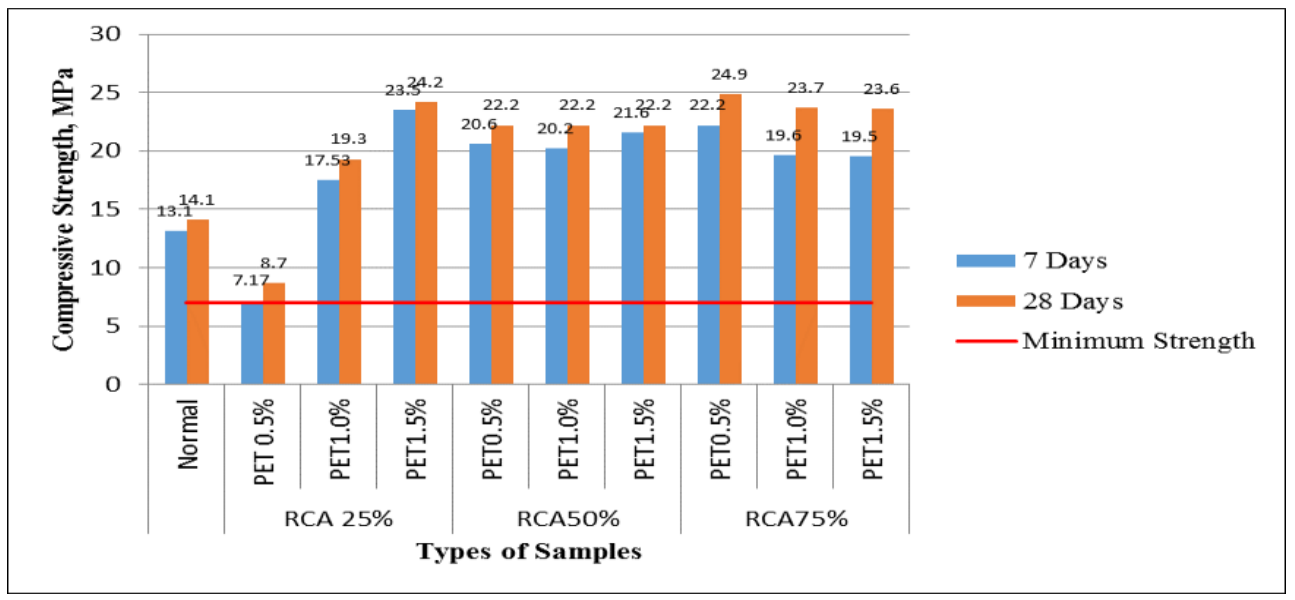

Fig. 2. Compressive Strength at 7 and 28 Days.

All the samples achieve strength more than the minimum strength for both 7 Days and 28 Days as BS 6073-1:1981 stated that the compressive strength of bricks should not be less than $7 \mathrm{~N} / \mathrm{mm}^{2}$. It is obviously showing that some samples for both curing age achieved high strength from the normal brick. The sample with RCA 25\% with PET $1.5 \%$ exhibit the second highest strength whereas RCA 25\% with PET 0.5\% achieve only $7.17 \mathrm{MPa}$ which is more lower strength rather than normal brick. Nevertheless, the specimen with RCA of $25 \%$, it shows the strength increased in line with the increasing of PET volume for $0.5 \%$, $1.0 \%$ and $1.5 \%$.

The increasing pattern of compressive strength is seen to be in samples containing RCA $75 \%$ for both curing age include 7 and 28 days. The addition of $0.5 \%$ PET with $75 \%$ of RCA gives the highest strength among the other samples. The reduction of strength is shown when the volume of PET increase from $1.0 \%$ to $1.5 \%$ for RCA $75 \%$. In addition, the highest percentage of increment strength between 7 days to 28 days among other samples is 
$17.30 \%$ and $17.37 \%$ respectively for $75 \%$ of RCA with a volume of PET for $1.0 \%$ and $1.5 \%$.

Moreover, the results reveal that only certain amount of PET fiber increase the strength with an addition of RCA of $25 \%, 50 \%$ and $75 \%$. The trend of this study having the same pattern with the studied conducted by Irwan et al. [2] and Noorwirdawati et al. [13] that stated the good bonding between aggregate and binder as an increase in synthetic plastic content may result a decreasing in strength of materials.

\subsection{Water absorption}

Water absorption was carried out to determine the percentage of water absorption of the brick. The details result of water absorption against age for each percentage of RCA and PET were given in Fig. 3. It shows the evolution of water absorption from 7 days to 28 days for all mixtures. The results illustrated that the water absorption increased with the replacement percentage of fine aggregate by the RCA and PET wastes for all mixtures. However, up to RCA50\%PET1.0\% replacement, a slight decreased of water absorption of composite cement brick for both 7 and 28 days. The results indicate that the sample with RCA50\%PET1.0\% was less permeable when compared to other samples. Furthermore, the highest water absorption coefficients were obtained in composite sand cement brick with RCA75\%PET1.5\%. Samples with $75 \%$ of RCA absorbed more water than did samples containing $50 \%$ and $25 \%$ of RCA.

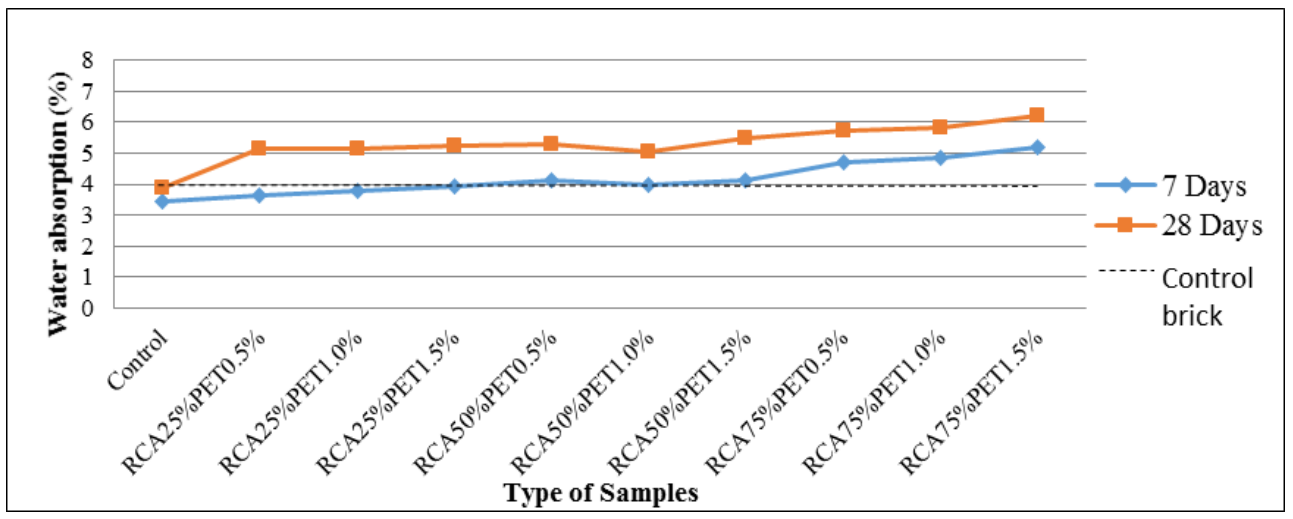

Fig. 3. The average water absorption of composite sand cement bricks with RCA and PET versus ages.

\section{Conclusions}

As the conclusion, the result can be concluded that the reduction in bricks density was attributed by the lower unit weight of RCA and PET. The sand replacement ratio of RCA and PET at levels $75 \%$ and $0.5 \%$ has good effects on the compressive strength of the bricks. From the result of water absorption, composite sand cement bricks with recycled fine aggregate and PET significantly affected the increased water absorption characteristic of bricks. However, only bricks with $50 \%$ RCA and 1.0\% PET show less permeable compared to control brick. 
This work was financially supported by University Tun Hussein Onn Malaysia (UTHM) and Minister of Education Malaysia (KPM) through Dana Pembudayaan Penyelidikan (RAGS) Vot. No. R058.

\section{References}

1. W. Kubissa, R. Jaskulski, A. Koper, J. Szpetulski, Procedia Engineering. 108, 30-38 (2015).

2. J.M. Irwan, S.K. Faisal, N. Othman, M.H. Wan Ibrahim, R.M. Asyraf, M.M.K. Annas, Adv. Mater. Res. 795, 352-355 (2014a).

3. P.N. Mazenan, F.S. Khalid, S. Shahidan, S. Shamsuddin, IOP Conf. Series: Materials Science and Engineering. 271 (2017).

4. O.Y. Marzouk, R.M. Dheilly, M. Queneudec, Waste Management. 27, 310-318 (2007).

5. J.M. Irwan, M.M.K. Annas, A.K. Aeslina, R.M. Asyraf, S.K. Faisal, Adv. Mater. Res., 911, 474-478 (2014b).

6. K. Ramadevi, R. Manju, International Journal of Engineering Technology and Advanced Engineering 2(6), 139-150 (2012).

7. V. Kumar, M. K. Poonia, V. S. Saggu, International Journal for Technological Research In Engineering 2(11), 2684-2689 (2015).

8. N. B. Azmi, F. S. Khalid, J. M. Irwan, N. Anting, P. N. Mazenan, IOP Conf. Series: Materials Science and Engineering 271 (2017).

9. L. Evangelista, J. D. Brito, Cem. Concr. Res. 29, 397-401 (2007).

10. J. M. Khatib. Cem. Concr. Res. 35, 763-769 (2005).

11. S. Yehia, K. Helal, A. Abusharkh, A. Zaher, H. Istaitiyeh, International Journal of Concrete Structures and Materials 9 (2), 219-239 (2015).

12. J.M. Irwan, R.M. Asyraf, S.K. Faisal, N. Othman, Wan Ibrahim M.H., Applied Mechanics And Materials 7, 911 (2015).

13. N. Ali, N. Din, F. S. Khalid, S. Shahidan, S. R. Abdullah, A. A. Abdul Samad, N. Mohamad, IOP Conf. Series: Materials Science and Engineering 271 (2017). 